WP 17-03-01*

\title{
The Impact of Taxes and Wasteful Government Spending on Giving
}

\author{
Roman M. Sheremeta \\ Weatherhead School of Management \\ Case Western Reserve University \\ Neslihan Uler \\ University of Maryland \\ Department of Agricultural and Resource Economics
}

^Note: This paper supersedes UMD-AREC-WP17-03.pdf

Copyright (C) 2020 by Roman M. Sheremeta and Neslihan Uler

All rights reserved. Readers may make verbatim copies of this document for non-commercial purposes by any means, provided that this copyright notice appears on all such copies. 


\title{
The Impact of Taxes and Wasteful Government Spending on Giving
}

\author{
Roman M. Sheremeta ${ }^{\text {a,b }}$ \\ Neslihan Uler ${ }^{c, *}$ \\ ${ }^{a}$ Weatherhead School of Management, Case Western Reserve University \\ 11119 Bellflower Road, Cleveland, OH 44106, USA \\ ${ }^{\mathrm{b}}$ Economic Science Institute, Chapman University \\ One University Drive, Orange, CA 92866, USA \\ ${ }^{c}$ Agricultural and Resource Economics, University of Maryland \\ 7998 Regents Dr, College Park, MD 20742, USA
}

May 22, 2020

\begin{abstract}
We examine how taxes impact charitable giving and how this relationship is affected by the degree of wasteful government spending. In our model, individuals make donations to charities knowing that the government collects a flat-rate tax on income (net of charitable donations) and redistributes part of the tax revenue. The rest of the tax revenue is wasted. The model predicts that a higher tax rate increases charitable donations. Surprisingly, the model shows that a higher degree of waste decreases donations (when the elasticity of marginal utility with respect to consumption is high enough). We test the model's predictions using a laboratory experiment with actual donations to charities. We find that the tax rate has an insignificant effect on giving. The degree of waste, however, has a large, negative and highly significant effect on giving.
\end{abstract}

JEL Classifications: C93, D64, H21

Keywords: charitable giving, tax, waste, redistribution, experiment, public goods provision, neutrality, income inequality

*Corresponding author: Neslihan Uler, neslihan@umd.edu.

We thank James Alm, Yan Chen, Rachel Croson, Emel Filiz-Ozbay, Enda Hargaden, Charles Holt, Rowell Huesmann, Daniel Hungerman, Steve Leider, John List, Charles Longfield, Yusufcan Masatlioglu, Yesim Orhun, Laura Razzolini, Anya Samek, Joel Slemrod, Nat Wilcox, seminar participants at the University of Chicago, the University of Michigan, the 2015 Economic Science Association Conference, and the 2015 Science of Philanthropy Initiative Annual Conference. We thank the John Templeton Foundation, the Science of Philanthropy Initiative, and the University of Maryland for financial support. Andrew Card, Yulia Chhabra, Juyeon Ha, Zedekiah Higgs, and Ethan McCall provided excellent research assistance. We also thank John Jensenius and Pak Ho Shen for their help with programming the experiment. 


\section{Introduction}

Polls conducted in the US show that people believe that part of tax revenue is wasted by the government. According to a 2014 Gallup Poll, Americans estimate that the federal government wastes $51 \%$ of each tax dollar. ${ }^{1}$ Similarly, according to a HuffPost/YouGov poll conducted in 2013, 69\% of Americans think that most of the federal budget deficit could be eliminated by cutting "waste and fraud," where examples of wasteful government spending include salaries and perks for government employees, foreign aid, and military spending. ${ }^{2}$

In this paper, we investigate how taxation affects charitable giving in the presence of a redistributive government that wastes part of the tax revenue. Our paper makes two novel contributions to the literature. First, while a sizable literature studies the relationship between tax rates and (tax-exempt) donations using empirical data, to our knowledge we are the first to study the impact of the tax rate on charitable giving using a controlled experiment with actual donations. Moreover, we study the relationship between the tax rate and charitable giving by systematically varying how much of the tax revenue is redistributed back to individuals, ranging from no redistribution to full redistribution. ${ }^{3}$ Second, we study the impact of wasteful government spending on giving. We show that when part of the tax revenue is wasted (instead of being redistributed back to individuals), both the price of giving and the net income of individuals depend not only on the tax rate but also on the degree of waste. By keeping the tax rate constant, we study the effect of changing the rate of waste on donations.

To examine how taxes impact giving and how this relationship is affected by the wastefulness of government spending, we provide a game-theoretic model. In our model, a public good is provided through private contributions by individuals. The government's role is to collect a flat-rate tax on income net of contributions to the public good and to redistribute the tax revenue. During redistribution, part of the collected tax revenue is wasted (e.g., the government spends this money on things that the individuals do not value).

As the tax rate increases, both the price of tax-deductible charitable giving and the income of contributors decrease, creating an ambiguous effect on donations. Consistent with previous theoretical and empirical literature, our model predicts that under weak assumptions the substitution effect dominates the income effect and, hence, there is a positive relationship between charitable donations and the tax rate (keeping the level of waste constant). In other words, our model shows that the results of the previous literature regarding the relationship between tax rate

\footnotetext{
${ }^{1}$ See http://www.gallup.com/poll/176102/americans-say-federal-gov-wastes-cents-dollar.aspx. The estimated rate of waste differs across Republicans and Democrats, with Republicans estimating 59 cents and Democrats estimating 42 cents per dollar. To isolate the effect of waste on giving, we consider a simple model with individuals being homogeneous with respect to their perceptions of the rate of waste.

2 See http://www.huffingtonpost.com/2013/03/18/wasteful-spending-poll_n_2886081.html. Based on the survey responses the article argues that "for many, waste is indeed defined as 'money spent on some government program I don't like'." Note that these perceptions may exogenously change over time depending on government actions or even through simple debates (e.g., discussions of wasteful government spending during elections may heighten individuals' perception about waste).

${ }^{3}$ To our knowledge, previous theoretical and empirical models on the impact of tax rates on donations assume one of the two extreme cases. For example, empirical literature typically makes a simplifying assumption that individuals do not receive any return from their paid taxes. Previous models are, therefore, special cases of our model.
} 
and giving continues to hold even if there is wasteful governmental spending. The other novelty of our model is to study the relationship between the level of waste and donations to charities. A change in the rate of waste also creates opposing substitution and income effects. While one might expect donations to the privately provided public good (charity) to increase as the government wastes more of the tax revenue, our model demonstrates the opposite might be true. We show that although increasing the degree of waste creates a small decrease in the price of giving, the negative income effect might be relatively sizable. Our model shows that, depending on the elasticity of marginal utility with respect to consumption, the income effect may dominate the substitution effect when the rate of waste increases. In addition, we show that, in large economies, the income effect always dominates the substitution effect when the degree of waste increases, leading to a negative relationship between the rate of waste and donations.

We test our model using an experiment with actual donations to charities. As opposed to naturally occurring data, our controlled environment removes the possibility of differences in beliefs about how tax revenue is used, changes in income over time, as well as other potential confounding factors which one usually needs to control for when estimating the impact of taxes on charitable donations (e.g., Andreoni and Payne, 2013). In our experiment, participants earn income, part of which they can donate to a charity. Participants choose their donations knowing that a flat-rate tax will be applied to their remaining income, with part of the collected tax revenue going back to the experimenter and the remaining portion being evenly redistributed among the participants. By varying the level of taxes and how much of the tax revenue is wasted (i.e., money received neither by charities nor by participants), we are able to isolate and test the impacts of the tax rate and wasteful tax revenue spending on giving in a controlled setting.

Our results show that the tax rate has an insignificant effect on giving. The degree of waste, however, has a large, negative and highly significant effect on giving. Consistent with the theoretical predictions, we find that the relationship between giving and waste depends on the elasticity of marginal utility. In addition, we find that our results do not depend on the initial income distribution. ${ }^{4}$ Moreover, we conduct an additional experiment as a robustness check and confirm that charitable giving is insensitive to the tax rate even when subjects are given a learning opportunity through repetition and feedback.

Our study has important policy implications. We find that, on average, the relationship between the tax rate and donations is economically small and statistically insignificant, suggesting that changes in taxes may not affect charitable giving as suggested by previous literature. In addition, the degree of waste plays a large role in giving decisions. Our experiment shows that even when the number of people in a given group is very small, the average effect of wasteful government spending on giving is negative. Our theory predicts that for larger economies the effect of wasteful government spending will be even more negative. Increasing the efficiency with which tax revenues are used, as well as providing individuals with better information on public services

\footnotetext{
${ }^{4}$ Our paper also contributes to the literature on income inequality and public goods provision (e.g., Chan et al., 1996, 1999; Anderson et al. 2008; Uler, 2011; Maurice et al., 2013; Duquette and Hargaden, 2019). We find qualitative support for the neutrality result of Bergstrom et al. (1986).
} 
financed by tax revenues, could help generate a substantial increase in charitable giving. Finally, tax rates might endogenously affect perceptions about wasteful government spending. For example, if individuals perceive that higher taxes imply more waste, then we may actually see a decrease (not an increase) in charitable donations as taxes increase. Empirical studies estimating price and income elasticities of giving would benefit from controlling for the confounding effect of perceptions about wasteful government spending.

Before we discuss the previous literature, we want to comment on three important points. First, for simplification purposes, this paper focuses on the redistributive role of the government, i.e., we assume that the tax revenue is being redistributed. Since redistribution is a special form of a (publicly provided) public good, it is not difficult to generalize the model to allow for the government to provide any public good, as long as the public good provided by the government is different than that provided by the charity. The only difference is that, in the latter case, our results would condition on the utility over the public good provided by the government (instead of on the consumption utility). Second, our theoretical results rely on the assumption that the charity and the government provide different public goods. If the government uses tax revenue to provide the same public good as the charity (or to provide a grant to the charitable organization), then a higher tax rate always leads to lower donations to the charity when the level of waste is fixed, and a higher rate of waste by the government always leads to higher donations to the charity when the tax rate is fixed. ${ }^{5}$ The reason for observing a negative relationship between the tax rate and donations (and a positive relationship between waste and donations) when government provides the same public good is because governmental provision and charitable provision are perfect substitutes. While this case is also interesting, this paper focuses on the case where government and the charity provide different public goods. ${ }^{6}$ This allows us to predict a positive relationship between donations and the tax rate, consistent with the large empirical literature on this topic (Andreoni, 2006; Vesterlund, 2016). Third, one might argue that individuals simply do not think about receiving a direct return from their paid taxes and consider their taxes as forgone money (even if they do not think there is wasteful government spending). This interpretation is actually a special case of our model.

We discuss related literature in Section 2. In Section 3, we present our theoretical model and develop testable hypotheses. Section 4 discusses our experimental design and procedures. Section 5 provides our results. Section 6 introduces a robustness check experiment and provides our findings. Section 7 provides a short discussion and concludes the paper.

\section{Literature Review}

In the United States, individual (private) donations constitute one of the major sources of revenue for many charities. Since most charitable donations are tax-deductible, a higher tax rate affects charitable giving in two major ways. On the one hand, because of deduction benefits, higher

\footnotetext{
${ }^{5}$ These predictions follow immediately from the crowding-out literature (e.g., Andreoni, 1993; Bolton and Katok, 1998; Eckel et al., 2005; Li et al., 2011).

${ }^{6}$ One important example of public goods where individuals make donations, but the government does not, is giving to religious organizations.
} 
taxes decrease the price of giving, which leads to a positive effect on giving (the substitution effect). On the other hand, higher taxes reduce after-tax net income, which has a negative effect on donations (the income effect). The empirical literature provides mixed findings on the magnitude of the net effect (Clotfelter, 1985, 1990; Randolph, 1995; Auten et al., 2002; Peloza and Steel, 2005; Bakija and Heim, 2011; Hungerman and Ottoni-Wilhelm, 2016; Duquette, 2016). ${ }^{7}$

Earlier empirical studies using cross-sectional data argue that a tax cut leads to a decrease in charitable giving. In particular, Clotfelter $(1985,1990)$ estimates the price elasticity to be greater than one in absolute value and the income elasticity to be less than one. Using panel data, Randolph (1995) finds that charitable giving is relatively insensitive to price changes, suggesting that permanent changes in the price of giving have a small effect on voluntary contributions. In contrast, Auten et al. (2002) find a substantially larger permanent-price elasticity using a different estimation technique. More recently, Bakija and Heim (2011) and Duquette (2016) find that the price elasticity of giving is greater than one in absolute value, while Hungerman and OttoniWilhelm (2016) report a price elasticity of 0.2. Estimates of price and income elasticities like those discussed above are very sensitive to the estimation techniques and the data sets being used, since observational data suffer from problems of identification and measurement. The net effect of taxation on charitable donations is still not clearly understood (Andreoni, 2006; List, 2011; Vesterlund, 2016).

A theoretical foundation for the impact of redistributive taxation on charitable giving has been provided by Warr (1982) and Bergstrom et al. (1986). These papers show that purely redistributive taxation (that does not change the set of contributors) should have no effect on total public goods provision. ${ }^{8}$ Uler (2009) extends the standard model by assuming that charitable donations to the public good are tax-deductible and, therefore, redistribution takes place over income net of contributions. The model demonstrates that, under a general class of utility functions, the substitution effect dominates the income effect. Hence, charitable giving increases when the tax rate increases. These models, however, have not addressed the case of wasteful government spending (i.e., the case when part of the tax revenue is wasted).

In addition to these empirical and theoretical studies, a number of experimental papers have analyzed how price and income affect individuals' giving. Most experimental studies find that, as predicted by economic theory, giving moves inversely with price (Andreoni and Vesterlund, 2001; Andreoni and Miller, 2002). ${ }^{9}$ For example, Eckel and Grossman (2003) conduct a laboratory

\footnotetext{
${ }^{7}$ Some of these papers study a related (but different) question. They ask how responsive total giving is to taxdeductibility and provide estimates of price-elasticity only. Theoretically, it is easy to show that the impact of taxdeductibility on donations is always positive, since tax-deductions make it cheaper to donate and individuals have more income to give. In other words, there are no opposing forces when it comes to the effect of tax-deductibility on donations.

${ }^{8}$ This result would not hold if individuals are impure-altruists (Andreoni, 1990). Impure altruism models explain why crowding-out is not complete when government provides public funds to charities. Interestingly, Hungerman (2014) shows that when individuals hide income, this creates a deadweight loss and leads to a surprising finding: warm-glow implies more crowding-out in a setting where individuals can evade taxes.

${ }^{9}$ Andreoni and Vesterlund (2001) focus on gender differences in altruism and show that men are more price sensitive. Andreoni and Miller (2002) show that preferences for altruism can be explained by rational models.
} 
experiment in which participants choose how much to contribute to a charity under different rebate and match rates and find that contributions (received by the charity) move inversely with price. ${ }^{10}$ Eckel and Grossman (2008) replicate their laboratory findings in a natural field setting. Similarly, Karlan and List (2007) find a negative relationship between price and giving (within a certain range of prices). In particular, they find that offering to match contributions $(\$ 1: \$ 1)$ increases individual giving, but further lowering the price by offering larger match ratios $(\$ 3: \$ 1$ and $\$ 2: \$ 1)$ has no additional impact on giving (not including the match). ${ }^{11}$ Huck and Rasul (2011) report price elasticities between -0.53 and -1.12 and Filiz-Ozbay and Uler (2019) find price elasticities in the range of -0.3 to -0.9 . Experimental evidence about the relationship between income and giving is mixed. Eckel and Grossman (2003, 2008), Eckel et al. (2007) and Rey-Biel et al. (2018) find a positive relationship between income and giving, while other studies find a negative relationship (Erkal et al., 2011) or no significant relationship at all (Andreoni and Vesterlund, 2001; Buckley and Croson, 2006). ${ }^{12}$

None of these experimental studies are in the context of taxation, however. While previous experimental literature is helpful to understand how individuals react to changes in prices and incomes, it is hard to extrapolate from these studies how individuals will react to changes in tax rates or wasteful government spending. The impact of the rebate or match rate on total donations received by the charity is different than the impact of the rate of tax or waste. ${ }^{13}$ Moreover, individuals might respond to lower income very differently when lower income is a consequence of a higher tax rate.

In the study most related to ours, Uler (2011) examines the relationship between the tax rate and individual contributions within a laboratory public goods setting. In public goods game experiments, donations have explicit monetary benefits for each participant, while charitable contributions in the field do not usually generate analogous monetary benefits. More importantly, a public goods game enforces a particular payoff structure and does not allow for estimation of the actual net effect of a tax rate change on donations to real charities. As such, the results of Uler (2011) may not be generalizable to charitable giving decisions in the real world (Levitt and List, 2007). Our paper provides a more realistic set-up in which subjects make actual charitable donations. In addition, we allow for the possibility of wasteful government spending and

\footnotetext{
${ }^{10}$ They also find that subjects are sensitive to how a subsidy is framed. Other studies comparing subsidy types include Davis et al. (2005), Davis and Millner (2005), Eckel and Grossman (2006a, 2006b), and Blumenthal et al. (2012).

${ }^{11}$ Duquette and Hargaden (2019), on the other hand, find a positive relationship between the match rate and donations even for very large values of the match rate.

${ }^{12}$ Auten et al. (2000) argue that the relationship between income and donations is U-shaped.

${ }^{13}$ Theoretically, assuming a concave consumption utility, when considering rebates or matches offered by a third party, an increase in the rebate or match rate always leads to higher total donations received by the charity (including the matches). To intuitively see why increasing the rebate/match rate does not lead to ambiguous effects on donations received by the charity the way increasing the rate of tax or waste does, consider the following examples. When the rebate (or match) rate increases, an individual might still choose to donate nothing and consume his/her available wealth. When a tax rate increases, however, the individual's net income strictly decreases even when he/she does not donate anything to the charity. Alternatively, when the rebate (or match rate) increases, an individual can donate the same (total) level as before and enjoy a higher net income. In contrast, when the tax rate increases, if the individual donates the same level as before, then he/she will definitely have a lower net income.
} 
systematically vary the degree to which individuals receive benefits from the tax revenue. Finally, we also study the direct impact of the rate of waste on donations, keeping the tax rate constant.

To isolate the effects of the tax rate and wasteful government spending on giving, our experimental study controls for two important confounding factors that are difficult to control for when using naturally occurring data. First, wasteful government spending may provoke tax evasion which might in turn affect charitable donations. Barone and Mocetti (2011) find that individuals' attitudes towards paying taxes are more favorable when resources are spent more efficiently, and Alm et al. (2016) show that corruption results in higher levels of tax evasion. Our experimental design eliminates tax evasion as a potential confounding factor by automatically taxing all participants in the experiment. Second, there is the possibility that tax rates affect labor supply decisions; see Saez et al. (2012) for a survey of this literature. Our experimental design eliminates this confounding factor by assigning income to participants prior to informing them that part of this income will be taxed. ${ }^{14}$

\section{The Theoretical Model and Hypotheses}

\subsection{The Model}

We consider an environment with one private good, one pure public good, and $n>1$ agents. The public good is provided privately through charitable contributions. Each agent $i$ has an income of $y_{i}$ units of a private good, and contributes (donates) $g_{i}$ to the public good. One unit of the public good can be produced by one unit of the private good. Therefore, the level of public good provision is equal to total contributions, i.e., $G=\sum_{i=1}^{n} g_{i}$. The total income in the economy is denoted by $Y=\sum_{i=1}^{n} y_{i}$.

The government collects a flat-rate tax $t, 0 \leq t \leq 1$, on income net of charitable contributions towards the public good and redistributes the tax revenue equally across the $n$ agents. During redistribution, part of the collected tax revenue $w, 0 \leq w \leq 1$, is wasted. ${ }^{15}$ Therefore, individual $i$ 's private consumption $c_{i}$, after contributing to the public good, paying his/her taxes and receiving any refund from the government, is given by:

$$
c_{i}=(1-t)\left(y_{i}-g_{i}\right)+(1-w) \frac{t \sum_{j=1}^{n}\left(y_{j}-g_{j}\right)}{n} \text {. }
$$

Individual preferences are represented by an additively separable utility function $u\left(c_{i}\right)+$ $v(G)$, where $u($.$) and v($.$) are strictly increasing, strictly concave, twice continuously$ differentiable functions and satisfy the Inada conditions. Finally, to simplify the analysis, we assume everyone contributes to the public good in the equilibrium. This assumption is reasonable as long as the ex-ante wealth inequality between agents is not very large (Bergstrom et al., 1986;

\footnotetext{
${ }^{14}$ Before the experiment started, subjects were told that they may lose part of the money they earn in Part 1 , but they were not explicitly told about the income taxation until Part 2 (see Appendix B).

${ }^{15}$ One can think of the "waste" as either the government funding programs that the individuals do not care for, or inefficient spending.
} 
Uler, 2009). Our results on the effects of the tax rate and the degree of waste on giving, however, do not depend on this assumption. ${ }^{16}$

Each individual chooses their contribution level, $g_{i}$, by taking other individuals' contributions as given. The first-order condition for an individual $i$ is given by:

$$
u^{\prime}\left(c_{i}\right)\left(1-\left(1-\frac{1-w}{n}\right) t\right)=v^{\prime}(G) .
$$

Since the right hand side of this equation is the same for each individual, we can infer that, in equilibrium, all agents consume the same amount of the private good. Note that this implies that the "neutrality" result of Bergstrom et al. (1986) also holds in this model: total public goods provision does not depend on the initial income distribution. ${ }^{17}$ The first-order condition simplifies to:

$$
u^{\prime}\left((1-w t)\left(\frac{Y-G}{n}\right)\right)\left(1-\left(1-\frac{1-w}{n}\right) t\right)=v^{\prime}(G)
$$

This condition is intuitive. Each agent chooses the level of contribution that would equalize the marginal benefit of contributing to the marginal cost of an additional unit of contribution. Note that the equilibrium is uniquely determined. ${ }^{18}$

The first question we seek to address is what happens to contributions when the tax rate increases for a given degree of waste. Equation (3) shows that higher taxes have two opposing effects on the equilibrium level of contributions: (i) a higher tax rate implies a lower price of giving, which has a positive effect on contributions (the substitution effect), and (ii) a higher tax rate implies lower net income, which has a negative effect on contributions (the income effect). To solve for the net effect of taxes on giving, we differentiate equation (3) with respect to the tax rate $t$ and then solve for $\frac{\partial G}{\partial t}$ :

$$
\frac{\partial G}{\partial t}=-\frac{u^{\prime \prime}(b) w\left(\frac{Y-G}{n}\right)(1-a t)+u^{\prime}(b) a}{v^{\prime \prime}(G)+u^{\prime \prime}(b)\left(\frac{1-w t}{n}\right)(1-a t)},
$$

where $a=\left(1-\frac{1-w}{n}\right)$ and $b=(1-w t)\left(\frac{Y-G}{n}\right)$. Since the denominator is always negative, the sign of the numerator determines the sign of the partial derivative of $G$ with respect to $t$.

\footnotetext{
${ }^{16}$ Our main results do not change when we allow for non-contributors. In particular, the sufficient conditions provided in Theorems 1-3 stay the same. For example, take Theorem 1. Under the sufficient condition provided in Theorem 1, for a given degree of waste, it is possible to show that i) as $t$ increases, the set of contributors (weakly) increases and ii) $\frac{\partial G}{\partial t}>0$ for any $t$. Similarly, all of our corollaries continue to hold. The only small adjustment that needs to be done is for Theorem 4. While the threshold provided in Theorem 4 becomes larger when we allow for non-contributors, it can be shown that it is still strictly less than 1 . In addition, it is not difficult to show that, for a given rate of tax, i) as $w$ increases, the set of contributors (weakly) decreases, and ii) $\frac{\partial G}{\partial w}<0$ for any $w$.

${ }^{17}$ Similar to Bergstrom et al. (1986), this result holds only when the set of contributors does not change as the initial income distribution changes. If the set of contributors changes when the initial income distribution changes, then the model would predict higher contributions when income inequality increases. Hence, similar to Bergstrom et al. (1986) and Uler (2009), there is a trade-off between contributions and (initial) income equality.

${ }^{18}$ This can be seen by using equation (1) and the fact that each individual consumes the same amount of the private good.
} 
When $w=0$, the income effect disappears (i.e., $u^{\prime \prime}(b) w\left(\frac{Y-G}{n}\right)(1-a t)$ becomes zero) and the positive relationship between $G$ and $t$ holds without any additional assumptions about the curvature of consumption utility (also see Uler, 2009). When $w>0$, however, whether the relationship between total public goods provision and the tax rate is positive or not depends on the curvature of the consumption utility. Our first theorem, generalizing the findings of Bergstrom et al. (1986) and Uler (2009), follows:

Theorem 1: For a given degree of waste, $0 \leq w<1$, if $u(x)$ satisfies $-\frac{u^{\prime \prime}(x) x}{u^{\prime}(x)} \leq 1$, then the total public good provision $G$ is a strictly increasing function of the tax rate $t$. When $w=1, G$ is a strictly increasing function of the tax rate, if $-\frac{u^{\prime \prime}(x) x}{u^{\prime}(x)}<1$.

To simplify the presentation of the paper, all proofs are provided in the online appendix (see Appendix A). Theorem 1 shows that whether individuals increase their donations when the tax rate increases depends on the elasticity of the marginal utility with respect to consumption, given by $-\frac{u^{\prime \prime}(x) x}{u^{\prime}(x)} \cdot{ }^{19}$ Note that in environments that involve risk, the elasticity of the marginal utility corresponds to the relative risk aversion coefficient.

Corollary 1: If the agents' consumption preferences are defined by the Constant Relative Risk Aversion (CRRA) utility function, $u=\frac{x^{(1-\theta)}}{(1-\theta)}$ for $0<\theta \neq 1$ and $u=\ln (x)$ for $\theta=1$, then, for a given degree of waste $0 \leq w<1$ and for $\theta \leq 1$, public good provision strictly increases as the tax rate increases. When $w=1$, public good provision strictly increases as the tax rate increases, if $\theta<1$.

The conditions provided in Theorem 1 and Corollary 1 are mild. In fact, as we will explain in Sections 3 and 4, we approximate individuals' elasticities of marginal utility with respect to consumption by using data from the risk elicitation task we used in our experiment. We find that only seven subjects have an elasticity coefficient greater than one. Therefore, one would expect the substitution effect to dominate the income effect as the tax rate increases. Theorem 1 and Corollary 1 are, however, silent regarding the magnitude of the net effect.

Next, we study whether $\frac{\partial G}{\partial w}$ is smaller or larger than $\frac{\partial G}{\partial t}$. Equation (3) shows that a higher degree of waste has two opposing effects on the equilibrium level of contributions: (i) a higher degree of waste implies a lower price of giving, which has a positive effect on contributions (the

${ }^{19}$ Note that $\frac{u^{\prime \prime}(x) x}{u^{\prime}(x)}=\frac{\frac{d u^{\prime}(x)}{d x} x}{u^{\prime}(x)}=\frac{\frac{d u^{\prime}(x)}{u^{\prime}(x)}}{\frac{d x}{x}}$. Therefore, the elasticity of the marginal utility with respect to consumption can also be interpreted as the sensitivity of the marginal rate of substitution between private consumption and public good consumption to price changes: the derivative of the marginal rate of substitution with respect to the price of private consumption (see Mirrlees, 1971). We are grateful to Daniel Hungerman for this insight. 
substitution effect), and (ii) a higher degree of waste implies a lower net income, which has a negative effect on contributions (the income effect). The substitution effect is always higher for the tax change than the wasteful spending change, which can be seen by examining the relative change in the price of giving generated by these two variables. The effect of a small change in the tax rate on the price of giving is given by $\left(1-\frac{1-w}{n}\right)$, whereas the effect of a small change in the rate of waste on the price of giving is given by $\frac{t}{n}$. Since $\left(1-\frac{1-w}{n}\right)$ is always greater than $\frac{t}{n}$ for any $t$ and $w$, the substitution effect in the case of waste $w$ is smaller than the substitution effect in the case of tax rate $t$. It is also easy to see that the income effect of increasing the degree of waste is at least as large as the income effect of increasing the tax rate when $t \geq w$. Therefore, for any $t \geq$ $w$, the net effect of the tax rate on public goods provision is always larger in the relative sense than the net effect of the rate of waste. ${ }^{20}$ It is, however, challenging to see how $\frac{\partial G}{\partial w}$ compares with $\frac{\partial G}{\partial t}$ for $t<w$. Theorem 2 shows that, if the elasticity of the marginal utility function with respect to consumption is less than or equal to one, then the marginal effect of increasing the tax rate on giving is larger than the marginal effect of increasing the degree of waste on giving, independent of the degree of waste and the tax rate.

Theorem 2: If $u(x)$ satisfies $-\frac{u^{\prime \prime}(x) x}{u^{\prime}(x)} \leq 1$, then $\frac{\partial G}{\partial t}>\frac{\partial G}{\partial w}$ for any $0<t \leq 1$ and $0 \leq w \leq 1$.

While Theorem 2 provides us with the relative comparison of the marginal effects of $t$ and $\mathrm{W}$, it does not inform us regarding the sign of $\frac{\partial G}{\partial w}$. To solve for the net effect of $w$ on giving while fixing the tax rate, we differentiate equation (3) with respect to $w$ and then solve for $\frac{\partial G}{\partial w}$ :

$$
\frac{\partial G}{\partial w}=-\frac{u^{\prime \prime}(b) t\left(\frac{Y-G}{n}\right)(1-a t)+u^{\prime}(b) \frac{t}{n}}{v^{\prime \prime}(G)+u^{\prime \prime}(b)\left(\frac{1-w t}{n}\right)(1-a t)} .
$$

Since the denominator in equation (5) is always negative, the sign of the numerator determines the sign of the partial derivative of $G$ with respect to $w$. Theorem 3 provides the sufficient condition for the substitution effect to dominate the income effect. Given the result in Theorem 2, one would expect to have a more restrictive sufficient condition in order to have a positive relationship between $G$ and $w$, and this is exactly what we see in Theorem 3 .

Theorem 3: For a given tax rate $0<t \leq 1$, if $u(x)$ satisfies $-\frac{u^{\prime \prime}(x) x}{u^{\prime}(x)} \leq \frac{1}{n}$, then the total public good provision $G$ is a strictly increasing function of the degree of waste $w$.

\footnotetext{
${ }^{20}$ For example, if $\frac{\partial G}{\partial t}=0$ and $\frac{\partial G}{\partial w}=-4$, then the partial derivative of $G$ with respect to $t$ is greater than the partial derivative of $G$ with respect to $w$ in the relative sense.
} 
Note that the sufficient condition in Theorem 3 does not hold for any $n \geq 2$, if $u(x)$ is a CRRA utility function with $\theta>\frac{1}{2}$ (see Corollary 2).

Corollary 2: If the agents' consumption preferences are defined by the CRRA utility function $u=$ $\frac{x^{(1-\theta)}}{(1-\theta)}$ for $0<\theta \neq 1$ and $u=\ln (x)$ for $\theta=1$, then giving strictly increases when the degree of waste increases if $\theta \leq \frac{1}{n}$.

We also see that as $n$ increases it becomes harder to satisfy the sufficient condition provided in Theorem 3 and Corollary $2 .{ }^{21}$ For example, for agents with a CRRA utility function, this condition will not hold for any positive $\theta$ as $n \rightarrow \infty$. This important result suggests that, in large economies, the income effect dominates the substitution effect and leads to a negative relationship between the rate of waste and donations to the public good.

While Theorem 3 and Corollary 2 are useful in providing the sufficient condition for a positive relationship between donations and the rate of waste, they do not inform us when to expect a definite negative relationship. Theorem 4 derives a necessary and sufficient condition for the income effect to dominate the substitution effect for the CRRA utility functions. It shows that, under the CRRA utility function, donations decrease in the degree of waste if and only if $\theta>$ $\frac{(1-w t)}{(1-a t) n}$. Note that the condition in Theorem 4 is satisfied for any positive $\theta$ in very large economies.

Theorem 4: Suppose the agents' consumption preferences are defined by the CRRA utility function. Then, $\frac{\partial G}{\partial w}<0$ if and only if $\theta>\frac{(1-w t)}{(1-a t) n} \cdot{ }^{22}$

Corollary 3 shows that if individuals have logarithmic consumption utility, then charitable donations increase when the tax rate increases and they decrease when the degree of waste increases, independent of the size of the economy.

Corollary 3: If the agents' consumption preferences are given by $\ln (c)+v(G)$, where $\theta=1$, then (i) for a given $0 \leq w<1$, public good provision increases when $t$ increases, and (ii) for a given $0<t \leq 1$, public good provision decreases when $w$ increases.

Note that (i) is true because the sufficient condition in Theorem 1 is satisfied, and (ii) comes from Theorem 4 , since $\frac{(1-w t)}{(1-a t) n}<1$ for any $n \geq 2$. Corollary 3 illustrates a simple example where

\footnotetext{
${ }^{21}$ In the experiment, we have three people in our experimental society. If this condition does not hold for $n=3$, then we do not expect it to hold with $n>3$.

${ }^{22}$ Note that $\frac{1}{n} \leq \frac{(1-w t)}{(1-a t) n}<1$ for any $0 \leq w \leq 1$, and $0 \leq t \leq 1$.
} 
the substitution effect is stronger than the income effect as the tax rate increases, while the income effect dominates the substitution effect as the degree of waste increases.

Theorem 4 and Corollary 3 are surprising. They show that, when a change in the degree of waste is considered, the income effect dominates the substitution effect under some common utility functions. The intuition behind these results is the following: increasing the degree of waste has only a small effect on lowering the relative price (or opportunity cost) of donations, because individuals are not expected to get much direct return from paying their taxes. This is especially true when the size of the economy is large, since individuals mostly consider their paid taxes as lost money and governmental waste has little positive impact on the price of donations. On the other hand, taxes are used to provide a governmental public good (i.e., redistribution). But, if the government is wasting the tax revenue, individuals receive lower transfers and therefore get poorer. Given that individuals are poorer, they have less money to donate to charities. The income effect has a strong negative effect on donations.

Before discussing our hypotheses, we first mention that our results are not limited to purely altruistic agents. Alternatively, individuals might have warm-glow preferences, i.e., receive utility only from their own donations to the charity (Andreoni 1989, 1990). By using a CRRA formulation, it is not hard to show that all of our results continue to hold if the agents have warmglow preferences. ${ }^{23}$

\subsection{Hypotheses}

We derive five testable hypotheses. According to our model, total donations and individual donations move in the same direction. ${ }^{24}$ We state our hypotheses at the individual level in order to utilize our data set more effectively and to conduct robustness checks by controlling for individualspecific variables such as income and demographics.

Based on our Theorem 1, we conjecture that individual donations increase when the tax rate increases (see Hypothesis 1). ${ }^{25}$ Note that Hypothesis 1 is also consistent with the previous empirical literature that suggests a positive relationship with charitable giving and the tax rate.

Hypothesis 1: Individual giving increases when the tax rate $t$ increases.

Second, based on Theorem 2, we provide a hypothesis regarding the relative impact of the effects of the tax rate and the degree of waste on individual giving.

\footnotetext{
${ }^{23} \mathrm{We}$ assume individual $i$ 's utility function is given by: $\frac{c_{i}^{1-\theta}}{1-\theta}+\frac{g_{i}^{1-\theta}}{1-\theta}$ for $0<\theta \neq 1$ and $\ln \left(c_{i}\right)+\ln \left(g_{i}\right)$ for $\theta=1$. We find that total public goods provision, $G$, is equal to $\frac{(1-w t) Y}{(1-a t)^{\frac{1}{\theta}}+(1-w t)}$. It is not difficult to calculate $\frac{\partial G}{\partial t}$ and $\frac{\partial G}{\partial w}$, and confirm that all of our results continue to hold. Future research could generalize our findings beyond a CRRA formulation.

${ }^{24}$ This can be easily seen from equation (1) and the fact that, in equilibrium, all individuals enjoy the same net consumption. In the case of corner solutions, total donations and average individual donations move in the same direction.

${ }^{25}$ Recall that the condition provided in Theorem 1 is very mild and that only seven subjects did not satisfy this condition.
} 
Hypothesis 2: The marginal effect of the tax rate on giving is larger than the marginal effect of the degree of waste on giving.

Recall that Theorem 3 predicts that if the elasticity of marginal utility is smaller than or equal to $\frac{1}{n}$, then giving is an increasing function of the degree of waste. Theorem 4 states that if individuals have CRRA preferences and the elasticity of marginal utility is larger than $\frac{(1-w t)}{(1-a t) n}$, then giving should decrease when the degree of waste increases. ${ }^{26}$ Assuming our participants' elasticity of marginal utility is large enough, we conjecture that the relationship between giving and $w$ is negative.

Hypothesis 3: Individual giving decreases when the degree of waste $w$ increases.

While our model considers homogeneous agents, we also derive predictions for heterogeneous agents assuming that individuals believe others to have similar preferences to themselves (i.e., they believe everyone has the same utility function as themselves). For example, there is a large literature in psychology (and recently economics) showing that individuals demonstrate a false consensus bias, which implies that, even when actual preferences are heterogeneous, individuals may not realize this and they may be considering a relatively homogeneous environment. ${ }^{27}$ Therefore, we predict that a participant that has an elasticity of marginal utility smaller than or equal to $\frac{1}{n}$ increases their donations as $w$ increases, and a participant that has an elasticity of marginal utility larger than $\frac{(1-w t)}{(1-a t) n}$ decreases their donations as $w$ increases. Note that, however, elasticity coefficients of individuals are not directly observable. We use a risk elicitation task to approximate these coefficients, since our elasticity condition capturing the curvature of the consumption utility corresponds to the relative risk aversion coefficient in an environment that involves risk.

We used a series of 15 binary lottery choices, as shown in Table 2, to elicit individuals' coefficients of risk aversion (also see Section 4 for additional details). The coefficient of risk aversion is determined by the number of safe choices. Assuming a CRRA utility function, an individual with seven or more safe choices is risk averse. For example, seven safe choices corresponds to a relative risk aversion coefficient $\theta$ between 0.26 and 0.50 , and eight corresponds to a relative risk aversion coefficient $\theta$ between 0.50 and 0.74 . An individual who makes six safe choices is either slightly risk averse or risk neutral. An individual who makes five safe choices is either risk neutral or slightly risk loving. An individual with less than five safe choices is risk loving.

\footnotetext{
${ }^{26}$ When the parameters of our experiment are used, $\frac{(1-w t)}{(1-a t) n}$ varies between 0.33 and 0.67 . Therefore, if $\theta>0.67$, then giving is a strictly decreasing function of $w$. If $0.33<\theta<0.67$, then giving may sometimes increase and sometimes decrease depending on the parameters (see Tables C.1 and C.2).

${ }^{27}$ See Selten and Ockenfels (1998) and Charness and Grosskopf (2001) for a review of this literature.
} 
It is important to highlight that we do not expect elicited risk aversion coefficients to be a perfect measure of the elasticity parameters and, therefore, we treat these coefficients as approximations. ${ }^{28}$ Below we provide two hypotheses (Hypotheses 4 and 5) that approximate our theoretical predictions:

Hypothesis 4: A participant who chooses less than seven safe choices in the risk elicitation task increases their donations as $w$ increases.

Hypothesis 5: A participant who chooses more than seven safe choices in the risk elicitation task decreases their donations as $w$ increases.

By conducting an experiment with real donations, we have the needed control to test our hypotheses and examine the net effects of changing the tax rate and the degree of waste on charitable donations.

\section{Experimental Design and Procedures}

The data come from an experiment conducted at the University of Michigan from AugustNovember 2015. A total of 204 students were recruited using the ORSEE software (Greiner, 2015). There were 12 sessions in total. Each session lasted one hour and fifteen minutes, on average, and had either 12 or 18 participants. The experiment proceeded in four parts and it was programmed using z-tree software (Fischbacher, 2007). The currency used in all parts of the experiment was U.S. dollars. Upon completion of the experiment, earnings from all parts of the experiment were added to a show-up payment of $\$ 5$. Participants received their payments in private and in cash, ranging from $\$ 15.50$ to $\$ 57.75$.

At the beginning of each part of the experiment, all participants were given written instructions (see Appendix B), and an experimenter read the instructions aloud. In part 1, participants took a 20-minute cognitive test containing 10 multiple-choice questions. The questions were drawn from a Graduate Record Examination (GRE) test preparation book (Seltzer, 2009). All were of moderate-to-high difficulty. Participants were told that they would gain one point for each correct answer and zero for an incorrect answer. Participants were also informed that, upon completion of part 1 , they would receive earnings which might depend on their relative performance in the test. ${ }^{29}$

\footnotetext{
${ }^{28}$ The elasticity of consumption utility coefficient may not be captured by the estimated relative risk aversion coefficient from the lottery task if agents are not expected utility maximizers or if the risk elicitation task used in the study does not correctly capture risk preferences. Nevertheless, in the absence of a better tool to capture elasticity of consumption utility, approximating the curvature of the consumption utility based on our risk elicitation task allows us to test the model in a stronger fashion. Since, in our experiment, donation decisions and risk elicitation tasks are performed under very similar conditions (including payoff levels for a given subject), it is not unreasonable for the behavior in the risk elicitation task to shed light on subjects' behavior regarding donation decisions.

${ }^{29}$ Specifically, participants were told that the amount earned "may be the same for everyone in this room, or each participant's earnings may depend on their relative performance in the test." We used this language to facilitate comparison between our two treatments: Equal versus Unequal.
} 
In part 2, participants were randomly and anonymously matched into groups consisting of 3 participants. We chose $n=3$ for two important reasons. First, it allows us to minimize mistakes/errors of experimental participants by creating the simplest possible environment for them while still keeping the environment rich enough to incorporate all the important factors that might influence their behavior. Second, it provides a strong test for the theory. For small values of $n$, the model makes different predictions depending on the elasticity of marginal utility.

Each group was randomly assigned to a different charity. ${ }^{30}$ Participants in a given group could simultaneously donate any amount to this charity, ranging from $\$ 0$ to the amount earned in part 1, in increments of 5 cents. In the Equal treatment, all members of the group received $\$ 30$. In the Unequal treatment, participants who scored the highest in part 1 received $\$ 45$, participants in the middle received $\$ 30$, and participants who scored the lowest received $\$ 15$. Note that the total amount of income is fixed across Equal and Unequal treatments $(\$ 30+\$ 30+\$ 30$ versus $\$ 45+\$ 30+\$ 15)$. While the Equal treatment provides a simple environment to test our predictions, the Unequal treatment provides a relatively more realistic set-up. It is important to stress that the focus of our study is the effect of changing the tax rates and degrees of waste on giving, but we are also able to study how income inequality affects giving decisions (keeping the rate of tax and waste constant).

Participants were asked to make 10 donation decisions at once under different combinations of the tax rate and the redistribution rate $(r=1-w)$, as shown in Table 1 . To avoid negative framing, we did not use the word "waste" in the experimental instructions. Participants were told that, at the end of the experiment, the computer would randomly implement one decision for payment, applying the appropriate tax and redistribution rates to compute the participant's payout. After the experiment, the experimenters sent a check to each charity for the total amount donated to that charity in that randomly determined decision. ${ }^{31}$

Participants knew that we would apply a tax (which was either $0 \%, 25 \%, 50 \%$, or $75 \%$ ) on each participant's remaining income and collect the corresponding amount of money. They also knew that we would evenly redistribute a share of the collected money among the participants within the same group, while the rest of the collected money (which was either $0 \%, 50 \%$, or $100 \%$ ) would be returned back to the experimenter. ${ }^{32}$ After learning their initial income, all participants made their donations simultaneously and anonymously. ${ }^{33}$ All ten donation situations were presented on the same screen. Given that we are primarily interested in the changes in donations as a response to the changing tax and waste rates (as opposed to the absolute donation amounts),

\footnotetext{
${ }^{30}$ We used the following charities: American Cancer Society, American Red Cross, Doctors Without Borders, Feeding America, Food for Poor, and Save the Children.

${ }^{31}$ Participants were told that, if requested, they would receive a confirmation email from the charity to verify that the experimenters sent their donations to the charity.

32 Instead of returning the funds to the experimenter, they could have instead been used to fund an alternative cause that would be perceived as wasteful by most subjects. Due to the difficulty of identifying a cause that would both be perceived as wasteful by subjects, while also not being a waste of limited research funds, we chose to avoid the design. Our design maximizes the effective use of limited research funds while achieving the objectives of this study.

${ }^{33}$ Tables $\mathrm{C} 1$ and $\mathrm{C} 2$ in Appendix $\mathrm{C}$ give theoretical predictions of giving for each $t$ and $w$ assuming specific utility functions.
} 
we made the changes as obvious as possible to the subjects. The subjects were free to make decisions in any order and revise their decisions before submitting them.

To minimize calculation mistakes, participants were provided with a pre-programmed "calculator". A participant could enter the tax rate, redistribution rate and the potential donation decisions by themselves and the other participants in their groups. The calculator would then show the group donation, pre-tax income, tax payment, after-tax income, redistribution amount and the final income of the participant. Participants could use the calculator as many times as they liked.

In part 3, we elicited participants' risk preferences (which we use as an approximation for their elasticity of marginal utility). Over a series of 15 binary choices, as shown in Table 2, participants were asked to choose between a risky option A ( $\$ 9.0$ or $\$ 1.0$ with $50 \%$ chance each) and a safe option B (increasing monotonically from $\$ 0.5$ to $\$ 7.5$ in increments of $\$ 0.50$ ). One of the 15 choices was randomly selected to be paid out at the end of the experiment. The parameters in this task were carefully designed to elicit a wide range of risk preferences.

In part 4, we elicited social preferences. Each participant was randomly matched with another participant. Participants were asked to choose one of the four options $(\$ 2.00 ; \$ 2.00)$, (\$1.75; \$3.00), (\$2.25; \$1.00) and $(\$ 2.00 ; \$ 1.75)$, where the first entry corresponds to their own payoff and the second entry corresponds to their paired participant's payoff. After both participants made their decisions, the computer randomly determined whose decision to implement, and the earnings of both participants were determined accordingly.

At the end of the experiment, participants filled out a demographic questionnaire. After the computer displayed outcomes from all parts of the experiment and calculated individual earnings, participants received their payments in private.

\section{Results}

Table 3 shows the average donation and the fraction of participants giving $\$ 0$ for different levels of tax and waste for both the equal and unequal income distributions. The left panel corresponds to the Equal treatment in which all participants received $\$ 30$ and could donate part of this income to a charity. The right panel corresponds to the Unequal treatment in which participants received either $\$ 45, \$ 30$, or $\$ 15$ (as determined by their relative performance in part 1 ). ${ }^{34}$ Note that, unless otherwise mentioned, we only consider the case of $t>0 \%$, since when $t=0 \%$, waste is no longer a consideration for participants (i.e., $w=N / A$ ).

We begin by examining how giving changes when $t$ changes. In the Equal treatment, when there is no waste $(w=0 \%)$, giving slightly increases from $\$ 3.97$ when $t=25 \%$ to $\$ 4.06$ when $t=50 \%$, and increases to $\$ 4.18$ when $t=75 \%$. None of these differences are significant based on pair-wise Wilcoxon signed-rank tests, however. Looking at the effect of higher taxes on giving at $w=50 \%$ and $w=100 \%$, we first see a decrease in giving and then an increase. While the first decrease at $w=50 \%$ is significant at the $1 \%$ significance level, none of the other cases are

\footnotetext{
347 participants ( 3 in the Equal and 4 in the Unequal treatment) received a score of zero in part 1. These subjects might have failed to submit their answers on time or simply chose not to work on the task. Our results are robust to inclusion or exclusion of these 7 participants and are available upon request from the authors.
} 
significant at the 5\% significance level. Pooling across all levels of waste, the left panel of Figure 1 shows no significant relationship between average giving and the tax rate $t$ in the Equal treatment (none of the three pair-wise comparisons are significant at the 5\% significance level).

Similar responses to changes in the tax rate are observed when examining the Unequal treatment. When there is no waste (i.e., $w=0 \%$ ), giving slightly increases from $\$ 4.75$ when $t=$ $25 \%$, to $\$ 4.90$ when $t=50 \%$ (p-value $=0.56$ ), and decreases to $\$ 4.57$ when $t=75 \%$ (p-value $=$ 0.03 ). Similarly, for $w=50 \%$, there is no monotonic relationship between the tax rate and giving. These differences are not significant based on pair-wise Wilcoxon signed-rank tests. For $w=$ $100 \%$, giving increases when the tax rate changes from $25 \%$ to $50 \%$, and from $50 \%$ to $75 \%$, but none of these increases are statistically significant. The right panel of Figure 1 shows that the line representing the relationship between the average donation and the tax rate in the Unequal treatment is virtually flat, suggesting no significant correlation (none of the three pair-wise comparisons are significant at conventional statistical levels).

Next, we examine how giving changes with $w$ using Wilcoxon signed-rank tests. In the Equal treatment, when the degree of waste increases from $w=0 \%$ to $w=50 \%$, giving significantly decreases from $\$ 3.97$ to $\$ 3.02$ when $t=25 \%$ (p-value $<0.01$ ), from $\$ 4.06$ to $\$ 2.53$ when $t=50 \%$ (p-value $<0.01$ ), and from $\$ 4.18$ to $\$ 2.85$ when $t=75 \%$ (p-value $<0.01$ ). When the degree of waste increases from $w=50 \%$ to $w=100 \%$, giving further decreases from $\$ 3.02$ to $\$ 2.06$ when $t=25 \%$ (p-value $<0.01$ ), from $\$ 2.53$ to $\$ 2.04$ when $t=50 \%$ (p-value $<0.01$ ), and from $\$ 2.85$ to $\$ 2.58$ when $t=75 \%$ (p-value $=0.06$ ). Pooling across all tax rates, the left panel of Figure 2 shows a clear negative and significant relationship between average giving and the degree of waste $w$ in the Equal treatment (all three pair-wise comparisons are significant at the 1\% significance level).

A similar response to changes in waste is observed when examining the Unequal treatment. When the degree of waste increases from $w=0 \%$ to $w=50 \%$, giving significantly decreases from $\$ 4.75$ to $\$ 3.58$ when $t=25 \%$ (p-value $<0.01$ ), from $\$ 4.90$ to $\$ 3.67$ when $t=50 \%$ ( -value $<0.01$ ), and from $\$ 4.57$ to $\$ 3.48$ when $t=75 \%$ (p-value $<0.01$ ). When the degree of waste increases from $w=50 \%$ to $w=100 \%$, giving further decreases from $\$ 3.58$ to $\$ 2.83$ when $t=$ $25 \%$ (p-value $<0.01$ ) and from $\$ 3.67$ to $\$ 2.85$ when $t=50 \%$ (p-value $<0.01)$, but it increases (although not significantly) from $\$ 3.48$ to $\$ 4.25$ when $t=75 \%$ (p-value $=0.12$ ). The right panel of Figure 2 shows that there is a clear negative and significant relationship between average giving and the degree of waste in the Unequal treatment (all three pair-wise comparisons are significant at the $1 \%$ significance level).

We now supplement the above nonparametric analysis with a series of regression analyses. Table 4 reports Tobit regressions with standard errors clustered at the participant level. ${ }^{35}$ The dependent variable is giving. Regression (1) uses the data from the Equal treatment, and the independent variables are the tax rate $t$ and the rate of waste $w$. Consistent with the non-parametric tests, the coefficient on $t$ is not significant ( $\mathrm{p}$-value $=0.68$ ). Also, consistent with the non-

\footnotetext{
${ }^{35}$ We choose to present Tobit regression analysis in the main text, since roughly half of the participants give $\$ 0$. Our qualitative results are robust to using OLS regressions (see Appendix D).
} 
parametric tests, the coefficient on $w$ is negative and significant at the $0.1 \%$ significance level, confirming that giving decreases in the degree of waste. Regression (2) uses the data from the Unequal treatment, and the independent variables are the tax rate $t$, the rate of waste $w$, and Income (to control for the different income levels that participants earned in part 1 of the experiment). As in the Equal treatment (regression 1), the coefficient on $t$ is not significant (p-value $=0.96$ ). Also, as in the Equal treatment, the coefficient on $w$ is negative and highly significant (p-value $<0.01$ ). Pooling the data from both treatments, as shown in regression (3) in Table 4, corroborates this result. Note that regressions (1)-(3) only consider data for $t>0 \%$ (since $w=N / A$ for $t=0 \%$ ). Alternatively, we can impose an assumption that $w=0 \%$ when $t=0 \%$. While this assumption is restrictive and may not accurately describe how participants perceive the case of $t=0 \%$, as a robustness check, we redid our analysis by imposing this assumption. Our results do not change (see regressions (4)-(6) in Table 4). The only difference is that the coefficient of the tax rate is now positive, but it is still not statistically significant. We provide additional robustness checks in Appendix D (see Tables D1-D4). ${ }^{36}$

Given our previous analysis, we can conclude that our data are consistent with Hypothesis 3 , but not consistent with Hypothesis 1. Both nonparametric tests and regression analysis fail to find a significant effect of the tax rate on giving. In contrast, we see a large and statistically significant negative effect of the degree of waste on donations in both nonparametric tests and regression analysis.

In order to test for Hypothesis 2, which states that the marginal effect of the tax rate on giving is greater than the marginal effect of the degree of waste on giving, we compare the coefficients on the tax rate and the rate of waste. Recall that, while the coefficient on the tax rate is not significantly different from zero, the coefficient on the rate of waste is negative and significant. Wald tests, formally testing Hypothesis 2 , show that the coefficient on $t$ is significantly larger than the coefficient on $w$ in all regressions (p-values in all of the tests are less than 0.01). We summarize our findings so far in Results 1-3:

Result 1: Giving does not change when the tax rate $t$ increases.

Result 2: The marginal effect of the tax rate on giving is significantly larger than the marginal effect of the degree of waste.

Result 3: Giving significantly decreases when the degree of waste $w$ increases.

Recall that our experimental design also gives us an opportunity to see how initial income inequality affects the level of contributions. We find that the coefficient of the dummy variable Unequal is not significant, suggesting that initial income distribution does not matter for giving decisions (Regressions (3) and (6) of Table 4). In addition, we get the same result if we instead perform non-parametric tests to compare giving between equal and unequal income distributions

\footnotetext{
${ }^{36}$ Appendix D also provides an analysis of heterogeneity among individuals.
} 
at each tax and waste level, i.e., p-values for all pairwise comparisons range between 0.20 and 0.77 (Wilcoxon rank-sum tests). This finding is consistent with the neutrality result of Bergstrom et al. (1986), which states that total public goods provision does not change with initial income inequality. ${ }^{37}$ It is important to note, however, that while the theory makes correct qualitative predictions at the aggregate level, it does not predict the levels of individual giving. While the model predicts that the high income individuals (who received \$45) should contribute more than the middle income individuals (who received \$30) and the middle income individuals should contribute more than the low income individuals (who received \$15), our regression analysis shows that this does not hold in the data. Although the Income coefficient in regressions (2) and (3) is positive, it is not significant (also see Tables D2-D3). In addition, when we run Tobit and OLS regressions with dummies for high and low income, none of our results change (Tables D5D6). The insignificant effect of income on giving may not be very surprising given that several other studies also find that high income individuals often under-contribute, while low income individuals often over-contribute relative to predicted levels (e.g., Chan et al., 1996, 1999; Uler, 2011; Maurice et al., 2013).

Next, we move on to test our Hypotheses 4 and 5. Recall that one of the theoretical predictions of our model is that the relationship between giving and the degree of waste depends on the curvature of subjects' utility functions with respect to consumption (or more formally the elasticity of marginal utility). The relationship between giving and the tax rate also changes sign depending on the elasticity of marginal utility with respect to consumption, but only for extremely high, not observed in practice, elasticity parameters. Also, recall that we use a risk elicitation task in order to approximate these elasticity parameters.

We find that the average number of safe choices in the risk elicitation task is 7.20 , with a standard deviation of 1.84. Hypothesis 4 states that individuals who choose less than seven safe choices will on average increase their giving as the degree of waste increases. Hypothesis 5 states that individuals who choose more than seven safe choices will on average decrease their giving as the degree of waste increases.

Table 5 reports the same regressions as those shown in Table 4, but considering only participants with more than 7 safe choices in regressions (1)-(3), and less than seven safe choices in regressions (4)-(6). ${ }^{38}$ Regressions (1)-(3) show that subjects with more than seven safe choices decrease their giving in the rate of waste $w .{ }^{39}$ Regressions (4)-(6) show that the magnitude and the significance of this relationship are greatly reduced when we consider subjects with less than seven

\footnotetext{
37 The neutrality result relies on the assumption that the set of contributors stays the same as income inequality increases. Otherwise, Bergstrom et al. (1986) (as well as our model) predicts that total giving increases as initial income inequality increases. Therefore, a stronger test of neutrality result requires to have a within-subject variation of income, but since this is not the main aim of the paper, we do not have such variation. We have recently come across a working paper by Duquette and Hargaden (2019), which studies the effect of income inequality on charitable donations by using within-subject variation.

38 One participant in our experiment has missing data after part 2 due to health reasons. Therefore, when we add variables from parts 3 and 4 and the questionnaires to the regression analysis, this participant gets automatically dropped from the regression analysis.

39 The negative impact of $w$ on giving is robust to including the subjects with seven safe choices.
} 
safe choices. These results are not consistent with Hypothesis 4, but they are consistent with Hypothesis 5. ${ }^{40}$ In Appendix D, we provide additional robustness checks (see Table D7).

Result 4: In contrast with Hypothesis 4, giving does not increase as the degree of waste increases for subjects that have a small elasticity of marginal utility (i.e., those that pick less than seven safe choices).

Result 5: Consistent with Hypothesis 5, giving decreases as the degree of waste increases for subjects with elasticity of marginal utility coefficients large enough (i.e., those that pick more than seven safe choices).

While we fail to find support for Hypothesis 4, it is important to note that the negative relationship between $w$ and giving completely disappears in regressions (5) and (6). This provides moderate support for the model, showing that curvature of the consumption utility affects the relationship between $w$ and giving.

Finally, we show that our results are robust to including several covariates. Table 6 reports Tobit regressions, in which the dependent variable is giving. For comparison purposes, regression (1) in Table 6 is the same as regression (3) in Table 4. Regression (2) in Table 6 uses two additional explanatory variables, Egalitarian and Generous. Egalitarian is a dummy variable that takes value 1 if a subject picked the fair option in part 4, and Generous is a dummy variable that takes value 1 if a subject picked the welfare maximizing option in part 4 . Note that the estimated coefficients on $w$ and $t$ in regression (2) are fairly similar to those in regression (1). In addition, we find that participants who are classified as Generous give more to charity (p-value < 0.01). Regression (3) adds other variables that were elicited at the end of the experiment using a survey. The positive and significant coefficient on Female suggests that, on average, women give more than men (pvalue $<0.01)$. Finally, regression (4) adds an additional control for the participant's score in part 1. Importantly, none of these controls change our main qualitative results. Table D8 confirms similar results using OLS regressions.

Result 6: Our results are robust to inclusion of control variables.

\section{An Additional Experiment for Robustness Check}

An important question arises. Why do we not see a positive relationship between the tax rate and charitable giving as predicted by our model? Perhaps we fail to find support for our hypothesis because we did not give our subjects an opportunity to learn. In this section, we test

\footnotetext{
${ }^{40}$ As a robustness check (not shown here for brevity), we have repeated our analysis by eliminating the 14 subjects that made less than six safe choices. Our qualitative results do not change.
} 
this possibility with an additional experiment and show that our results are robust to learning through repeated play and feedback. ${ }^{41}$

We have conducted an additional experiment with 90 new subjects during October 2019. This additional experiment also took place at the University of Michigan and consisted of five sessions. Each session lasted approximately one and a half hours and had 18 participants. Subjects are randomly divided into groups of three and the composition of the groups stay the same throughout the sessions.

Both the design and the instructions have only minimal deviations from the original study (see Appendix B for the instructions). The main differences can be summarized in three points: i) in order to give subjects the largest opportunity to learn and respond to the tax rate, the new study focuses only on changing the tax rate while keeping the rate of waste constant at $50 \%$, ii) subjects play 15 rounds of the game, with each tax rate $(25 \%, 50 \%$ or $75 \%)$ repeating five times, and iii) after subjects simultaneously and anonymously enter their charitable giving decisions for a given round, they are provided with feedback (i.e., subjects are informed of the total amount of donations made to the assigned charity by their own group, as well as their pre-tax income, tax payment, after-tax income, redistribution amount and final income). Similar to the original experiment, only one decision is randomly selected and implemented at the end of the experiment.

Since in the new experiment subjects make donation decisions one round at a time and feedback is provided between each round, the order in which different tax rates appear could affect behavior dramatically. We control for possible order effects by using the following mechanism: For each group, one of the possible tax rates is randomly selected for round one. Then, for the second round, a tax rate is randomly selected from the two remaining unused tax rates, and the other tax rate then appears in round three. This process repeats itself four more times to determine the tax rate for rounds $4-15$. This mechanism allows each group to face a random sequence of tax rates, such that each tax rate appears five times, and preserves the desirable feature that different tax rates are evenly distributed over rounds. Therefore, we can effectively control for order effects and guarantee that the level of experience and different tax rates cannot be correlated.

Table 7 shows, for a given tax rate: the mean donation, standard error and proportion of zero-donations, first calculated using the individual donations data from all 15 rounds, then using only the first three rounds and finally using only the last three rounds. Consistent with our previous finding, we do not see a positive effect of the tax rate on donations. The effect seems to be negative, if anything, when the first three rounds or all rounds are considered. When we look at the last three rounds, where subjects are the most experienced with the game, there does not appear to be a monotonic relationship between the tax rate and donations. In addition, Figure 3, which shows average donations over the five repetitions for each tax rate, similarly confirms the lack of a positive relationship.

\footnotetext{
${ }^{41}$ We thank Charles Noussair, who suggested that studying repeated decisions with feedback is essential to understanding whether the failure of donations to respond to the tax rate is a transitory phenomenon that would go away with better comprehension of the task or whether it is a durable and solid pattern of behavior.
} 
In order to test whether the differences in donations across tax rates are statistically significant, we conduct Wilcoxon signed-rank tests. We use data averaged at the group level as our independent observations. ${ }^{42}$ Table 8 shows the results. There is no evidence that donations significantly change as the tax rate changes at the 5\% significance level when we consider all 15 rounds, the first three rounds or the last three rounds. In other words, our results from the new experiment support our conclusions from the original experiment.

We provide further support by conducting a regression analysis (see Table 9). Specifications 1 and 2 of Table 9 report Tobit regressions with and without controls, respectively. Specifications 3 and 4 repeat the analysis in specifications 1 and 2 using OLS. Robust standard errors are clustered at the group level. All specifications show that contributions decline over rounds, which is a common result in public goods experiments. More importantly, donations increase with neither the tax rate nor income. These results are consistent with our previous findings in Section 5.

Result 7: We fail to find a significant impact of the tax rate on giving, even when subjects gain experience with repetition and receive feedback after each round.

\section{Discussions and Conclusion}

We provide a theoretical model and conduct a laboratory experiment to study how tax rates and waste impact individual giving. ${ }^{43}$ Our model demonstrates that the tax rate and the rate of waste create different effects on prices (the opportunity cost of giving). The effect of an increase in the tax rate on the price of giving is stronger than the effect of an increase in the rate of waste on the price of giving. We show that the model predicts that the marginal effect of the tax rate on giving is greater than the marginal effect of the degree of waste on giving. The theory shows that, while the relationship between charitable giving and the tax rate is positive, donations may increase or decrease when the rate of government waste increases (depending on the elasticity of marginal utility with respect to consumption). The data provide strong qualitative support for the model regarding the differential effects of the tax rate and waste on donations. Our experimental results show that changes in the tax rate $t$ have a weak and insignificant effect on giving. This finding is robust to repetition and feedback as shown by our robustness experiment. We also find that the degree of waste $w$ has a negative and highly significant effect on giving. Consistent with our theoretical predictions, the relationship between giving and $w$ changes across low and high levels of elasticity of marginal utility.

One might question why we fail to find support for Hypothesis 1 even though both Hypotheses 2 and 3 are consistent with the data. There are several competing explanations for this. First, it is possible that the elasticity of marginal utility with respect to consumption is greater than one. Second, subjects may not be willing to reduce the resources to be shared with their group

\footnotetext{
${ }^{42}$ Note that there are 30 independent groups.

${ }^{43}$ To isolate the effects of tax and waste on donations, our paper focuses on the demand side of giving. A related literature studies the factors that affect the supply side (e.g., Krasteva and Yildirim, 2016). Future research could incorporate how the supply side might also be affected from changes in the tax rate and the rate of waste.
} 
members, even when the price of giving to charity decreases (as the tax rate increases). Third, in the context of taxation, the positive substitution effect might not be very salient, while the income effect may be highly salient. Fourth, participants may experience negative emotions towards taxation, such as anger and/or distrust, since the money they rightfully earned is being "wasted", which may then lead to lower altruism towards charitable causes.

It is possible to largely rule out the first explanation, as very few subjects seem to have an elasticity of marginal utility higher than one (approximated by their coefficient of relative risk aversion). The second explanation can also be mostly ruled out, since we do not find a statistically significant increase in giving even when the rate of waste is constant at $100 \% .{ }^{44}$ Both the third and fourth explanations are consistent with why Hypothesis 1 is not supported by our data. ${ }^{45}$ It is possible that the saliency of income loss and negative emotions due to waste create behavioral biases that cancel out the positive effect predicted by the model and lead to the lack of a significant effect of the tax rate on giving. Note that, the same explanations are also consistent with why Hypothesis 4 is not supported. In addition, these explanations imply that the effect of increasing the degree of waste might be even more negative than suggested by our model.

These findings have important implications to policy. In a controlled environment, we show that the tax rate does not have a positive and significant effect on charitable donations. This suggests that the charities should not lower their fundraising efforts when there is an increase in the tax rate and the government should not rely on increasing the tax rate as an effective policy tool to increase the charitable pie. In addition, since our results imply that the average effect of "waste" on donations is negative in large economies, we conjecture that policies decreasing the transaction costs related to taxation are likely to increase charitable donations. Moreover, donations are likely to increase if individuals perceive tax revenue to be spent on services they value rather than things they do not care for. Silverman et al. (2014) argue that individuals evade taxes less if they are given a satisfying explanation for being taxed. Similarly, our findings suggest that it might be worthwhile to make an effort to convince individuals that their taxes are being efficiently used for public services. Finally, our results imply that empirical studies estimating price and income elasticities of giving would benefit from controlling for the confounding effect of perceptions about wasteful government spending, since perceptions regarding waste might exogenously or endogenously change over time.

\footnotetext{
${ }^{44}$ For each income distribution, we have run regressions (both Tobit and OLS) to study whether the impact of tax rate on donations is statistically significant when $w=1$. None of the regressions show a statistically significant effect of tax rate on donations at a 5\% significance level. When the data from different income distributions are pooled, then a significant impact can be seen in an OLS regression ( $\mathrm{p}$-value $=0.04$ ), but the result is not robust to using a Tobit regression analysis instead $(\mathrm{p}$-value $=0.79)$.

${ }^{45}$ Our experiment is not designed to differentiate between these alternative explanations. Future research could address this important research question.
} 


\section{References}

Alm, J., Martinez-Vazquez, J., \& McClellan, C. (2016). Corruption and firm tax evasion. Journal of Economic Behavior and Organization, 124, 146-163.

Anderson, L. R., J. M. Mellor and J. Milyo (2008). Inequality and public good provision: An experimental analysis. The Journal of Socio-Economics, 2008, 37 (3), 1010 -1028.

Andreoni, J. (1989). Giving with Impure Altruism: Application to Charity and Ricardian Equivalence. The Journal of Political Economy, 97, 1447-1458.

Andreoni, J. (1990). Impure altruism and donations to public goods: A theory of warm-glow giving. Economic Journal, 100, 464-477.

Andreoni, J. (1993). An experimental test of public-goods crowding out hypothesis. American Economic Review. 83, 1317-1327.

Andreoni, J. (2006). Philanthropy. Handbook of giving, reciprocity and altruism. Amsterdam: North Holland, pp. 1201-1269.

Andreoni, J., \& Miller, J. (2002). Giving according to GARP: An experimental test of the consistency of preferences for altruism. Econometrica, 70, 737-753.

Andreoni, J., \& Payne, A. (2013). Charitable giving. In Auerbach, A., Chetty, R., Feldstein, M., Saez, E. (ed.), Handbook of public economics. Amsterdam: North Holland, pp. 1-50.

Andreoni, J., \& Vesterlund, L. (2001). Which is the fair sex? Gender differences in altruism. Quarterly Journal of Economics, 116, 293-312.

Auten, G.E., Clotfelter, C., \& Schmalbeck, R.L. (2000). Taxes and philanthropy among the wealthy. In J. Slemrod (ed.), Does atlas shrug? The economic consequences of taxing the rich. New York and Cambridge, MA: Russell Sage and Harvard University Press, pp. 392-424.

Auten, G.E., Sieg, H., \& Clotfelter, C.T. (2002). Charitable giving, income, and taxes: An analysis of panel data. American Economic Review, 92, 371-382.

Bakija J., \& Heim, B. (2011). How does charitable giving respond to incentives and income? New estimates from panel data. National Tax Journal, 64, 615-650.

Barone, G., \& Mocetti, S. (2011). Tax morale and public spending inefficiency. International Tax and Public Finance, 18, 724-749.

Bergstrom, T., Blume, L., \& Varian, H. (1986). On the private provision of public goods. Journal of Public Economics, 29, 25-49.

Blumenthal, M., Kalambokidis, L., \& Turk, A. (2012). Subsidizing charitable contributions with a match instead of a deduction: What happens to donations and compliance? National Tax Journal, 65, 91-116.

Bolton G., \& Katok, E. (1998). An experimental test of the crowding out hypothesis: The nature of beneficent behavior. Journal of Economic Behavior and Organization, 37, 315-331.

Buckley, E., \& Croson, R. (2006). Income and wealth heterogeneity in the voluntary provision of linear public goods. Journal of Public Economics, 90, 935-955.

Chan, K.S., Mestelman, S., Moir, R., \& Muller, R.A. (1996). The voluntary provision of public goods under varying income distributions. Canadian Journal of Economics, 29, 54-69. 
Chan, K.S., Mestelman, S., Moir, R., \& Muller, R.A. (1999). Heterogeneity and the voluntary provision of public goods. Experimental Economics, 2, 5-30.

Charness, G., \& Grosskopf, B. (2001). Relative payoffs and happiness: An experimental study. Journal of Economic Behavior and Organization, 45 pages 301-328.

Clotfelter, C.T. (1985). Federal tax policy and charitable giving. Chicago: University of Chicago Press.

Clotfelter, C.T. (1990). The impact of tax reform on charitable giving: A 1989 perspective. In Do Taxes Matter, J. Slemrod (ed.), MIT Press, pp. 203-235.

Davis, D.D., \& Millner, E.L. (2005). Rebates and matches and consumer behavior. Southern Economic Journal, 72, 410-421.

Davis, D.D., Millner, E.L., \& Reilly, R.J. (2005). Subsidy schemes and charitable contributions: A closer look. Experimental Economics, 8, 85-106.

Duquette, N. (2016) Do tax incentives affect charitable contributions? Evidence from public charities' reported revenues. Journal of Public Economics, 137: 51-69.

Duquette, Nicolas and Hargaden, Enda (2019). Inequality and Giving. Available at SSRN: http://dx.doi.org/10.2139/ssrn.3227209

Eckel, C.C., \& Grossman, P.J. (2003). Rebate versus matching: Does how we subsidize charitable contributions matter? Journal of Public Economics, 87, 681-701.

Eckel, C.C., \& Grossman, P.J. (2006a). Do donors care about subsidy type? An experimental study. In D. Davis, \& M. Isaac (eds.), Research in experimental economics. New York: JAI Press, pp. 163-182.

Eckel, C.C., \& Grossman, P.J. (2006b). Subsidizing charitable giving with rebates or matching: Further laboratory evidence. Southern Economic Journal, 72, 794-807.

Eckel, C.C., \& Grossman, P.J. (2008). Subsidizing charitable contributions: A natural field experiment comparing matching and rebate subsidies. Experimental Economics, 11, 234-252.

Eckel, C.C., Grossman, P.J., \& Johnston, R. (2005). An experimental test of the crowding out hypothesis. Journal of Public Economics, 89, 1543-1560.

Eckel, C.C., Grossman, P.J., \& Milano, A. (2007). Is more information always better? An experimental study of charitable giving and hurricane Katrina. Southern Economic Journal, 74, $388-411$.

Erkal, N., Gangadharan, L., \& Nikiforakis, N. (2011). Relative earnings and giving in a real-effort experiment. American Economic Review, 101, 3330-3348.

Filiz-Ozbay, E. and N. Uler (2019) "Demand for Giving to Multiple Charities: An Experimental Analysis,” Journal of European Economic Association, Vol:17, Issue:3, Pages: 725-753.

Fischbacher, U. (2007). z-Tree: Zurich toolbox for ready-made economic experiments. Experimental Economics, 10, 171-178.

Greiner, B. (2015). Subject pool recruitment procedures: organizing experiments with ORSEE. Journal of the Economic Science Association, 1, 114-125.

Hungerman, D. (2014). Public goods, hidden income, and tax evasion: Some nonstandard results from the warm-glow model. Journal of Development Economics. 109, 188-202. 
Hungerman, D., \& Ottoni-Wilhelm, M. (2016). What is the price elasticity of charitable giving? Estimating (un)compensated elasticities from a tax-credit kink. Working Paper.

Karlan, D., \& List, J.A. (2007). Does price matter in charitable giving? Evidence from a large-scale natural field experiment. American Economic Review, 97, 1774-1793.

Krasteva S., and H. Yildirim (2016). "Information, Competition and the Quality of Charities." Journal of Public Economics, 144, 64-77.

Levitt, S.D., \& List, J.A. (2007). What do laboratory experiments measuring social preferences reveal about the real world? Journal of Economic Perspectives, 21, 153-174.

Li, S.X., Eckel, C.C., Grossman, P.J., \& Brown, T.L. (2011). Giving to government: Voluntary taxation in the lab. Journal of Public Economics, 95, 1190-1201.

List, J. (2011). The market for charitable giving. Journal of Economic Perspectives, 25, 157-180.

Maurice, J., Rouaix, A., \& Willinger, M. (2013). Income redistribution and public good provision: An experiment. International Economic Review, 54, 957-975.

Mirrlees, J.A. (1971). An exploration in the theory of optimal income taxation. Review of Economic Studies, 38, 175-208.

Peloza, J. and Steel, P. (2005) The price elasticities of charitable contributions: a meta-analysis. Journal of Public Policy \& Marketing, 24(2), 260-272.

Randolph, W. (1995). Dynamic income, progressive taxes, and the timing of charitable contributions. Journal of Political Economy, 103, 709-738.

Rey-Biel, P., Sheremeta, R.M., \& Uler, N. (2018). When income depends on performance and luck: The effects of culture and information on giving. Research in Experimental Economics, forthcoming.

Saez, E., Slemrod, J., \& Giertz, S.H. (2012). The elasticity of taxable income with respect to marginal tax rates: A critical review. Journal of Economic Literature, 50, 3-50.

Selten, R., \& Ockenfels, A. (1998). An experimental solidarity game. Journal of Economic Behavior and Organization, 34, 517-539.

Seltzer, N. (2009). 1,014 GRE Practice Questions. Princeton Review.

Silverman, D., Slemrod, J., \& Uler, N. (2014). Distinguishing the role of authority "In" and authority "To." Journal of Public Economics, 113, 32-42.

Uler, N. (2009). Public goods provision and redistributive taxation. Journal of Public Economics, 93, 440-453.

Uler, N. (2011). Charitable giving, inequality, and taxes. Experimental Economics, 14, 287-306.

Vesterlund, L. (2016). Voluntary Giving to Public Goods: Moving Beyond the Linear Voluntary Contribution Mechanism. in John Kagel and Alvin Roth (Eds.) Handbook of Experimental Economics, Vol 2, Princeton: Princeton University Press.

Warr, P.G. (1983). The private provision of a public good is independent of the distribution of income. Economics Letters, 13, 207-211. 
Table 1: Donation decisions in the experiment

\begin{tabular}{ccc}
\hline \hline Decision line & Tax rate, $t$ & Waste, $w$ \\
\hline 1 & $0 \%$ & N/A \\
2 & $25 \%$ & $0 \%$ \\
3 & $50 \%$ & $0 \%$ \\
4 & $75 \%$ & $0 \%$ \\
5 & $25 \%$ & $50 \%$ \\
6 & $50 \%$ & $50 \%$ \\
7 & $75 \%$ & $50 \%$ \\
8 & $25 \%$ & $100 \%$ \\
9 & $50 \%$ & $100 \%$ \\
10 & $75 \%$ & $100 \%$ \\
\hline
\end{tabular}

Participants choose how much to donate given the tax rate and the waste rate. Note that, in the experiment, to prevent negative framing, the rate of waste was presented as the "redistribution rate" $($ i.e., $1-w)$.

Table 2: Elicitation of risk preferences

\begin{tabular}{|c||c|c||c||c|}
\hline \multicolumn{1}{|c||}{$\begin{array}{c}\text { Decision } \\
\text { Line }\end{array}$} & \multicolumn{2}{c||}{ Option A } & Option B & $\begin{array}{c}\text { Choose } \\
\text { A or B }\end{array}$ \\
\hline 1 & $\$ 9.00$ with $50 \%$ chance & $\$ 1.00$ with $50 \%$ chance & $\$ 0.50$ for sure & \\
\hline 2 & $\$ 9.00$ with $50 \%$ chance & $\$ 1.00$ with $50 \%$ chance & $\$ 1.00$ for sure & \\
\hline 3 & $\$ 9.00$ with $50 \%$ chance & $\$ 1.00$ with $50 \%$ chance & $\$ 1.50$ for sure & \\
\hline 4 & $\$ 9.00$ with $50 \%$ chance & $\$ 1.00$ with $50 \%$ chance & $\$ 2.00$ for sure & \\
\hline 5 & $\$ 9.00$ with $50 \%$ chance & $\$ 1.00$ with $50 \%$ chance & $\$ 2.50$ for sure & \\
\hline 6 & $\$ 9.00$ with $50 \%$ chance & $\$ 1.00$ with $50 \%$ chance & $\$ 3.00$ for sure & \\
\hline 7 & $\$ 9.00$ with $50 \%$ chance & $\$ 1.00$ with $50 \%$ chance & $\$ 3.50$ for sure & \\
\hline 8 & $\$ 9.00$ with $50 \%$ chance & $\$ 1.00$ with $50 \%$ chance & $\$ 4.00$ for sure & \\
\hline 9 & $\$ 9.00$ with $50 \%$ chance & $\$ 1.00$ with $50 \%$ chance & $\$ 4.50$ for sure & \\
\hline 10 & $\$ 9.00$ with $50 \%$ chance & $\$ 1.00$ with $50 \%$ chance & $\$ 5.00$ for sure & \\
\hline 11 & $\$ 9.00$ with $50 \%$ chance & $\$ 1.00$ with $50 \%$ chance & $\$ 5.50$ for sure & \\
\hline 12 & $\$ 9.00$ with $50 \%$ chance & $\$ 1.00$ with $50 \%$ chance & $\$ 6.00$ for sure & \\
\hline 13 & $\$ 9.00$ with $50 \%$ chance & $\$ 1.00$ with $50 \%$ chance & $\$ 6.50$ for sure & \\
\hline 14 & $\$ 9.00$ with $50 \%$ chance & $\$ 1.00$ with $50 \%$ chance & $\$ 7.00$ for sure & \\
\hline 15 & $\$ 9.00$ with $50 \%$ chance & $\$ 1.00$ with $50 \%$ chance & $\$ 7.50$ for sure & \\
\hline
\end{tabular}

Table 3: Individual giving by treatment

\begin{tabular}{|c|c|c|c|c|c|}
\hline \multicolumn{2}{|c|}{ Treatment } & \multicolumn{2}{|c|}{ Equal } & \multicolumn{2}{|c|}{ Unequal } \\
\hline Tax rate, $t$ & Waste, $w$ & Average giving & Fraction of $\$ 0$ & Average giving & Fraction of $\$ 0$ \\
\hline $0 \%$ & N/A & $\$ 3.69(0.52)$ & 0.50 & $\$ 3.83(0.64)$ & 0.50 \\
\hline $25 \%$ & $0 \%$ & $\$ 3.97(0.57)$ & 0.46 & $\$ 4.75(0.65)$ & 0.39 \\
\hline $50 \%$ & $0 \%$ & $\$ 4.06(0.55)$ & 0.44 & $\$ 4.90(0.66)$ & 0.39 \\
\hline $75 \%$ & $0 \%$ & $\$ 4.18(0.59)$ & 0.46 & $\$ 4.57(0.66)$ & 0.39 \\
\hline $25 \%$ & $50 \%$ & $\$ 3.02(0.44)$ & 0.47 & $\$ 3.58(0.51)$ & 0.43 \\
\hline $50 \%$ & $50 \%$ & $\$ 2.53(0.39)$ & 0.50 & $\$ 3.67(0.60)$ & 0.46 \\
\hline $75 \%$ & $50 \%$ & $\$ 2.85(0.54)$ & 0.52 & $\$ 3.48(0.61)$ & 0.50 \\
\hline $25 \%$ & $100 \%$ & $\$ 2.06(0.38)$ & 0.61 & $\$ 2.83(0.54)$ & 0.56 \\
\hline $50 \%$ & $100 \%$ & $\$ 2.04(0.45)$ & 0.67 & $\$ 2.85(0.58)$ & 0.58 \\
\hline $75 \%$ & $100 \%$ & $\$ 2.58(0.60)$ & 0.70 & $\$ 4.25(0.93)$ & 0.61 \\
\hline
\end{tabular}

Standard error of the mean is in parentheses. 
Table 4: Tobit regression of giving

\begin{tabular}{lcccccc}
\hline \hline & \multicolumn{3}{c}{ For $t>0 \%$} & \multicolumn{3}{c}{ For all $t$} \\
\cline { 2 - 6 } Treatment & Equal & Unequal & Pooled & Equal & Unequal & Pooled \\
\hline Dependent variable, giving & $(1)$ & $(2)$ & $(3)$ & $(4)$ & $(5)$ & $(6)$ \\
\hline$t$ & -0.46 & -0.07 & -0.27 & 0.34 & 1.46 & 0.94 \\
$\quad$ [tax rate] & $(1.11)$ & $(1.23)$ & $(0.85)$ & $(1.09)$ & $(1.20)$ & $(0.83)$ \\
$w$ & $-4.26^{* * *}$ & $-3.92^{* * *}$ & $-4.13^{* * *}$ & $-4.06^{* * *}$ & $-3.56^{* * *}$ & $-3.83^{* * *}$ \\
$\quad$ [degree of waste] & $(1.05)$ & $(1.12)$ & $(0.79)$ & $(0.95)$ & $(0.97)$ & $(0.70)$ \\
Income & & 0.02 & 0.03 & & 0.02 & 0.03 \\
$\quad$ income $\$ 15, \$ 30, \$ 45]$ & & $(0.08)$ & $(0.08)$ & & $(0.08)$ & $(0.08)$ \\
Unequal & & & 1.66 & & & 1.52 \\
$\quad[1$ if the Unequal treatment] & & & $(1.33)$ & & & $(1.31)$ \\
Constant & 1.47 & 0.95 & -0.30 & 0.91 & -0.31 & -1.24 \\
$\quad$ [constant term] & $(1.22)$ & $(2.49)$ & $(2.79)$ & $(1.11)$ & $(2.46)$ & $(2.77)$ \\
\hline Observations & 810 & 1026 & 1836 & 900 & 1140 & 2040 \\
\hline Clusters & 90 & 114 & 204 & 90 & 114 & 204 \\
\hline Note: * indicates statistical significance at $0.05, * *$ at 0.01, and $* * *$ at 0.001 level. Standard errors in parentheses are clustered \\
at the participant level.
\end{tabular}

Table 5: Giving and the curvature of the utility function

\begin{tabular}{|c|c|c|c|c|c|c|}
\hline \multirow[b]{2}{*}{ Treatment } & \multicolumn{3}{|c|}{ More than 7 safe choices } & \multicolumn{3}{|c|}{ Less than 7 safe choices } \\
\hline & Equal & Unequal & Pooled & Equal & Unequal & Pooled \\
\hline Dependent variable, giving & $(1)$ & $(2)$ & (3) & $(4)$ & $(5)$ & $(6)$ \\
\hline$t$ & 0 & -1.33 & -0.78 & -0.29 & 4.00 & 1.85 \\
\hline [tax rate] & $(1.43)$ & $(1.16)$ & $(0.90)$ & $(1.90)$ & $(2.76)$ & $(1.77)$ \\
\hline$w$ & $-4.25 * *$ & $-5.39 * *$ & $-4.92 * * *$ & $-2.46^{*}$ & -1.56 & -2.09 \\
\hline [degree of waste] & $(1.42)$ & $(1.99)$ & $(1.33)$ & $(1.16)$ & $(1.91)$ & $(1.15)$ \\
\hline Income & & -0.08 & -0.07 & & -0.10 & -0.07 \\
\hline$[$ income $=\$ 15, \$ 30, \$ 45]$ & & $(0.11)$ & $(0.11)$ & & $(0.13)$ & $(0.12)$ \\
\hline Unequal & & & 0.04 & & & 3.06 \\
\hline [1 if the Unequal treatment] & & & $(1.98)$ & & & $(2.16)$ \\
\hline Constant & 2 & 5.3 & 4.75 & -0.20 & 0.92 & -0.87 \\
\hline [constant term] & $(1.84)$ & $(2.78)$ & $(3.83)$ & $(2.03)$ & $(4.46)$ & $(4.41)$ \\
\hline Observations & 333 & 450 & 783 & 351 & 351 & 702 \\
\hline Clusters & 37 & 50 & 87 & 39 & 39 & 78 \\
\hline
\end{tabular}


Table 6: The determinants of giving

\begin{tabular}{|c|c|c|c|c|}
\hline Dependent variable, giving & (1) & (2) & (3) & (4) \\
\hline$t$ & -0.27 & -0.33 & -0.25 & -0.27 \\
\hline [tax rate] & $(0.85)$ & $(0.85)$ & $(0.84)$ & $(0.86)$ \\
\hline$w$ & $-4.13 * * *$ & $-4.14 * * *$ & $-4.08 * * *$ & $-4.16^{* * *}$ \\
\hline [degree of waste] & $(0.79)$ & $(0.79)$ & $(0.76)$ & $(0.78)$ \\
\hline Income & 0.03 & -0.02 & -0.01 & -0.02 \\
\hline$[$ income $=\$ 15, \$ 30, \$ 45]$ & $(0.08)$ & $(0.07)$ & $(0.07)$ & $(0.09)$ \\
\hline $\begin{array}{l}\text { Unequal } \\
\text { [1 if the Unequal treatment] }\end{array}$ & $\begin{array}{c}1.66 \\
(1.33)\end{array}$ & $\begin{array}{l}1.60 \\
(1.27)\end{array}$ & $\begin{array}{c}1.83 \\
(1.17)\end{array}$ & $\begin{array}{l}1.43 \\
(1.16)\end{array}$ \\
\hline Egalitarian & & 2.76 & 1.81 & 1.83 \\
\hline$[1$ if $(\$ 2.00 ; \$ 2.00)]$ & & $(1.82)$ & $(1.68)$ & $(1.70)$ \\
\hline Generous & & $7.71 * *$ & $7.92 * *$ & $7.86^{* *}$ \\
\hline$[1$ if $(\$ 1.75 ; \$ 3.00)]$ & & $(2.78)$ & $(2.41)$ & $(2.45)$ \\
\hline Hardwork & & & -0.53 & -0.52 \\
\hline [how hard you worked in part 1] & & & $(0.28)$ & $(0.27)$ \\
\hline Female & & & $3.89 * *$ & $3.89 * *$ \\
\hline [1 if female] & & & $(1.41)$ & $(1.40)$ \\
\hline Family income & & & 0.13 & 0.22 \\
\hline [family income] & & & $(0.32)$ & $(0.32)$ \\
\hline Right-wing & & & 0.78 & 0.71 \\
\hline [right-wing political view] & & & $(0.54)$ & $(0.56)$ \\
\hline Unnecessary & & & -3.63 & -3.04 \\
\hline [1 if taxes are annoying and unnecessary] & & & $(2.27)$ & $(2.30)$ \\
\hline Necessary & & & 0.13 & 1.53 \\
\hline [1 if taxes are necessary and do not bother] & & & $(2.60)$ & $(2.68)$ \\
\hline Reputation & & & 0.01 & -0.11 \\
\hline [importance of own reputation] & & & $(0.39)$ & $(0.40)$ \\
\hline Church & & & 0.72 & 0.61 \\
\hline [giving to church] & & & $(0.39)$ & $(0.39)$ \\
\hline Charity & & & 0.44 & 0.5 \\
\hline [giving to charities] & & & $(0.50)$ & $(0.51)$ \\
\hline Familiar & & & 0.30 & 0.28 \\
\hline [knowledge of charity] & & & $(0.24)$ & $(0.24)$ \\
\hline American & & & -0.41 & -0.34 \\
\hline [1 if a United States citizen] & & & $(1.56)$ & $(1.58)$ \\
\hline $\begin{array}{l}\text { Part } 1 \\
\text { [part } 1 \text { score] }\end{array}$ & & & & $\begin{array}{c}0.13 \\
(0.35)\end{array}$ \\
\hline Constant & -0.30 & -1.84 & -7.43 & -7.45 \\
\hline [constant term] & $(2.79)$ & $(3.06)$ & $(5.46)$ & $(5.40)$ \\
\hline Observations & 1836 & 1827 & 1827 & 1764 \\
\hline Clusters & 204 & 203 & 203 & 196 \\
\hline
\end{tabular}

Note: * indicates statistical significance at $0.05, * *$ at 0.01 , and ${ }^{* * *}$ at 0.001 level. Standard errors in parentheses are clustered at the participant level. 
Table 7: Giving-Robustness Check

\begin{tabular}{ccccccc}
\hline \hline & \multicolumn{2}{c}{ All 15 rounds } & \multicolumn{2}{c}{ First three } & \multicolumn{2}{c}{ Last three } \\
\hline Tax rate, $t$ & \multicolumn{2}{c}{ Average giving } & Fraction of $\$ 0$ & Average giving & Fraction of $\$ 0$ & Average giving Fraction of $\$ 0$ \\
\hline $25 \%$ & $\$ 3.18(0.22)$ & 0.63 & $\$ 4.12(0.53)$ & 0.70 & $\$ 2.50(0.47)$ & 0.56 \\
$50 \%$ & $\$ 2.95(0.19)$ & 0.63 & $\$ 3.73(0.47)$ & 0.68 & $\$ 2.55(0.44)$ & 0.56 \\
$75 \%$ & $\$ 2.93(0.22)$ & 0.56 & $\$ 3.62(0.55)$ & 0.61 & $\$ 2.50(0.44)$ & 0.49 \\
\hline $\mathrm{N}$ & 450 & 450 & 90 & 90 & 90 & 90 \\
\hline
\end{tabular}

Standard error of the mean is in parentheses.

Table 8: Wilcoxon Signed Rank Tests

\begin{tabular}{cccc}
\hline \hline & All 15 rounds & First three & Last three \\
\hline $25 \%$ vs $50 \%$ & 0.24 & 0.30 & 0.82 \\
$50 \%$ vs $75 \%$ & 0.92 & 0.09 & 0.87 \\
$25 \%$ vs $75 \%$ & 0.80 & 0.23 & 0.87 \\
\hline \multicolumn{2}{l}{ Note: For each test, sample size is 30 (i.e., there are 30 independent pairs). }
\end{tabular}

Table 9: Regression Analysis

\begin{tabular}{lcccc}
\hline \hline & \multicolumn{2}{c}{ Tobit } & \multicolumn{2}{c}{ OLS } \\
\hline Dependent variable, giving & $(1)$ & $(2)$ & $(3)$ & $(4)$ \\
\hline$t$ & -1.34 & -1.29 & -0.51 & -0.52 \\
[tax rate] & $(1.05)$ & $(1.04)$ & $(0.71)$ & $(0.73)$ \\
Income & 0.05 & 0.05 & 0.04 & 0.04 \\
$\quad$ income $=\$ 15, \$ 30, \$ 45]$ & $(0.05)$ & $(0.05)$ & $(0.03)$ & $(0.04)$ \\
Round & $-0.16^{* * *}$ & $-0.17 * * *$ & $-0.10^{* * *}$ & $-0.10^{* * *}$ \\
$\quad$ round $=1, \ldots, 15]$ & $(0.04)$ & $(0.04)$ & $(0.02)$ & $(0.02)$ \\
Constant & 1.59 & 0.72 & $2.72^{* *}$ & 2.45 \\
[constant term] & $(1.42)$ & $(4.37)$ & $(0.84)$ & $(2.47)$ \\
\hline Controls Added & No & Yes & No & Yes \\
\hline Observations & 1350 & 1335 & 1350 & 1335 \\
\hline Clusters & 30 & 30 & 30 & 30 \\
\hline Note: $*$ indicates statistical significance at $0.05, * *$ at 0.01, and $* * *$ at 0.001 level. Standard errors in parentheses \\
are clustered at the group level. Data for one subject is automatically dropped from the analysis when controls are \\
included in specifications 2 and 4, since this subject did not fill in the questionnaire. \\
\hline
\end{tabular}


Figure 1: Average giving in response to changes in $\boldsymbol{t}$

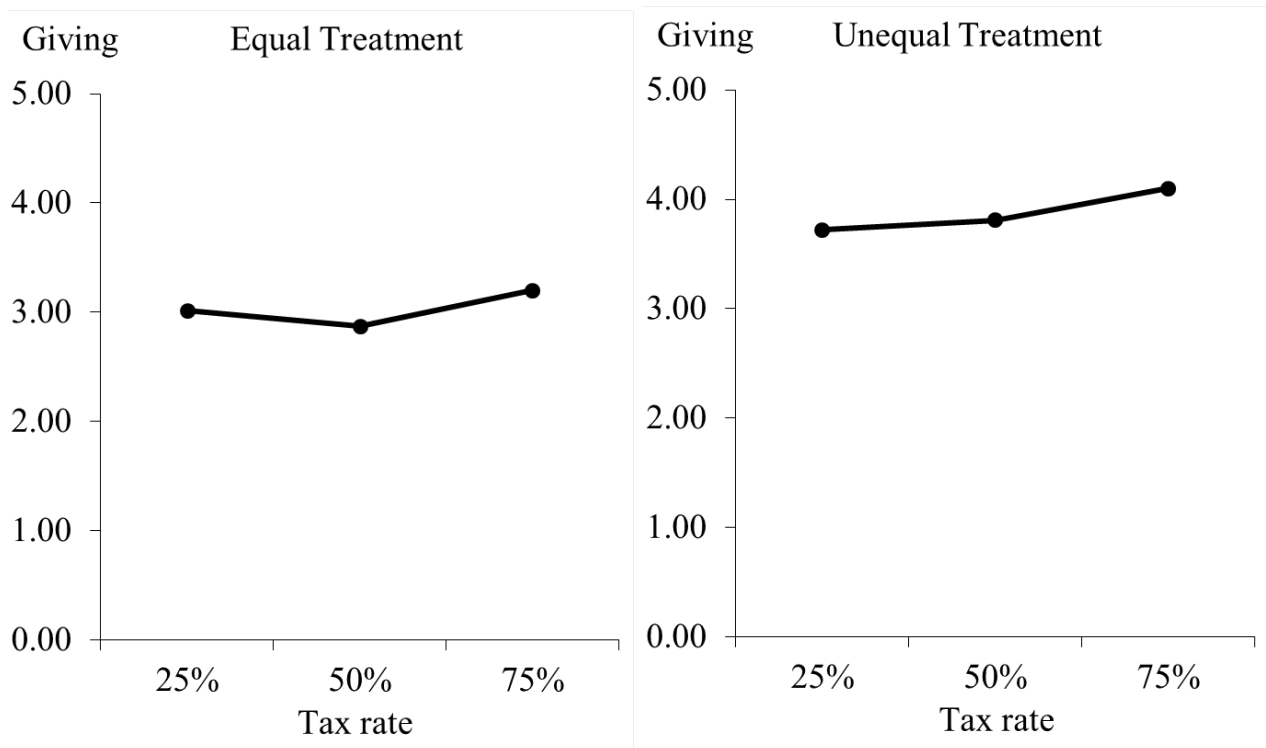

Figure 2: Average giving in response to changes in $w$
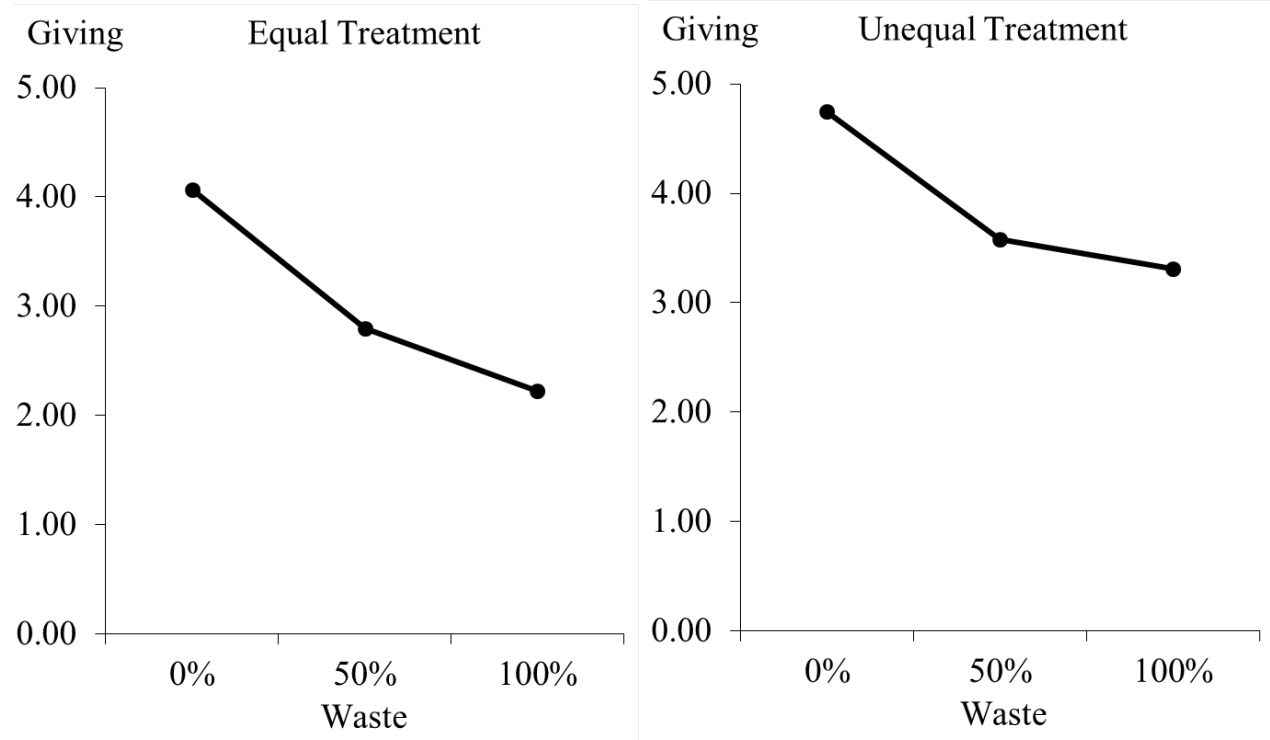
Figure 3: Average giving over repetitions

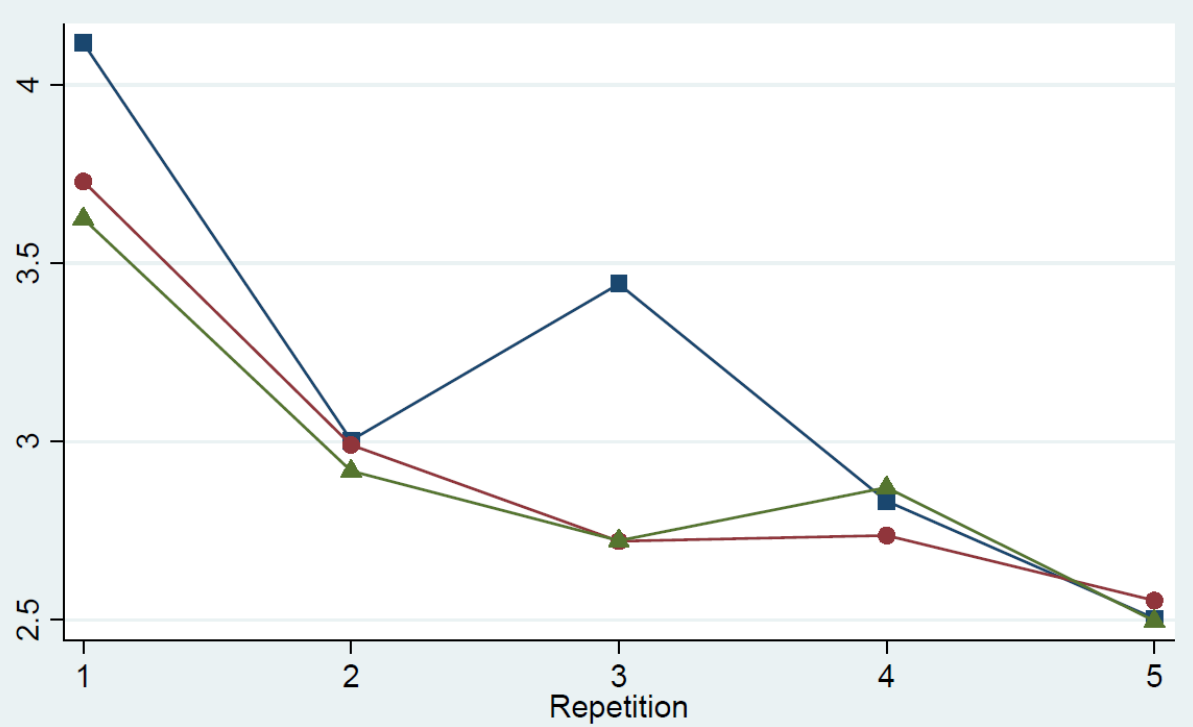

$\longrightarrow$ mean contribution at $25 \%$ tax $\longrightarrow$ mean contribution at $50 \%$ tax
- mean contribution at $75 \%$ tax 